\title{
Reaching Hispanic Audiences: What Can We Do as Extension Educators?1
}

Nick T. Place and Dilcia Toro ${ }^{2}$

Are you interested in offering programs to Hispanics but have found little interest from the Hispanic community to attend your programs?

Have you encountered barriers with Hispanic audiences, and wondered how can you break them down?

Have you wondered about the best ways for engaging Hispanics into your extension programs?

\section{Introduction and Background}

According to the US Census Bureau (2000), Florida is the fourth largest state, and Hispanics represent the largest minority group. The current population in the state of Florida consists of just over 17 million people, of which 2.8 million (16.8\%) are of Hispanic origin. Additionally, numerous Hispanics are migrant farmworkers working in Florida agricultural industries including dairy, livestock, vegetable production, nurseries and landscaping.

In general, many Hispanic farmworkers have a low education level. According to The National Agricultural Workers Survey 2001-02 published
March 2005, only 13 percent of migrant workers had completed 12 years of schooling. The median highest grade completed was the $7^{\text {th }}$ grade. Thirteen percent of migrant workers had completed less than 3 years of schooling. In addition, Spanish was the predominant language for $81 \%$ of migrant farm workers, followed by English (18\%).

Changing demographics and distinct cultural factors relevant to Hispanics have prompted the necessity for culture-specific programming (Knoche and Zamboanga 2003). As a nationwide educational network established through the Smith-Lever legislation in 1914, the US Cooperative Extension System faces the challenge of addressing the educational needs of migrant farmworkers. These efforts focus on offering relevant and appropriate training for the benefit of bettering their standard of living.

A well-developed program that assures that the target audience will be reached takes more than good educational material. A major part of the Hispanic population has low speaking and writing skills and literacy levels in both English and Spanish. This causes difficulty with communication and

1. This document is AEC-375, one of a series of the Agricultural Education and Communication Department, Florida Cooperative Extension Service, Institute of Food and Agricultural Sciences, University of Florida. Original publication date February 2006. Visit the EDIS Web Site at http://edis.ifas.ufl.edu.

2. Nick T. Place, associate professor, Department of Agricultural Education and Communication; Dilcia Toro, MS graduate student, Department of Agricultural Education and Communication; Florida Cooperative Extension Service, Institute of Food and Agriculture Sciences, University of Florida, Gainesville, FL 32611.

The Institute of Food and Agricultural Sciences (IFAS) is an Equal Opportunity Institution authorized to provide research, educational information and other services only to individuals and institutions that function with non-discrimination with respect to race, creed, color, religion, age, disability, sex, sexual orientation, marital status, national origin, political opinions or affiliations. U.S. Department of Agriculture, Cooperative Extension Service, University of Florida, IFAS, Florida A. \& M. University Cooperative Extension Program, and Boards of County Commissioners Cooperating. Larry Arrington, Dean 
understanding. Also many Hispanics are immigrants in an illegal status who move from place to place depending on work opportunities, and they are frequently placed in high-risk occupations and industry sectors. Nonetheless, engaging immigrant farm workers and their families in extension programs could have tremendous impact for them and their employers.

The remainder of this document provides useful information that will help those who serve Hispanic farmworkers and their families by providing guidelines that should be taken into account when designing a program for them. The guidelines are divided into three primary stages. These stages consist of planning, including all those activities done before a program actually starts; implementation, relating to the actual delivery of educational activities; and evaluation, consisting of determining the educational delivery strategies that will be most effective for a specific clientele group.

\section{Planning Stage}

When planning programs for Hispanic audiences we need to be aware that Extension education and nonformal education programs are not common across many Latin American countries. Consequently, many Hispanics are not familiar and not comfortable in engaging in nonformal education programs and its benefits. Therefore, it is best if the program is delivered or at least recommended by trusted sources, and it should be in a comfortable setting such as job sites and community organizations.

Hispanics face significant barriers due to their low education level that can cause difficulties with appropriate communication. Their cultural background, which is usually agricultural and poor, limits the amount of time available for activities other than work. Also, many Hispanics come to the U.S. without knowing about basic aspects of public health such as, tobacco cessation, birth control and HIV.

To address these issues and concerns begin by getting to know your targeted clientele and their specific needs.
- Involve community leaders as a starting point. Visit organizations that work with Hispanics such as the Coalition of Florida Farmworker Organizations (COFFO), churches and companies that hire Hispanic farm workers. They can share important information that can guide program planners for building a strong program, and they can also be useful in advertising the program.

- Consider working with established groups and other organizations where Hispanics already feel comfortable. This may include churches and social groups they attend such as the Farmworker Association of Florida, Inc. (FWAF) which is a membership organization of over 6,330 farmworker families in more than 11 counties in Florida. This association, since the early 90s, has addressed pesticides, field sanitation, and other health and safety issues, educating and training members to learn their rights, and justice issues for farmworkers (http://farmworkers.org). Another example is the National Farm Worker Ministry (NFWM), an interfaith organization that supports farm workers as they organize for empowerment, justice and equality throughout the country (http://nfwm.org) .

- Consider hiring the appropriate staff (or soliciting volunteers) to involve with delivery of the education program. Preferably they should be bilingual and able to relate to the background and experience of the program's participants (Bocanegra and Warrix 1998).

- Consider transportation time and costs as potential burdens for economically disadvantaged groups (Bocanegra and Warrix 1998). If possible, involve businesses to support participants in fee payment and transportation.

- Families and youth respond best to an invitation to participate if it is presented personally and by trusted sources. Use direct calling and send personal invitation letters when possible. Advertise widely in multiple ways. Prepare and hand out brochures and flyers about your local extension office and an invitation to specific programs that would be of interest to them. 
- Place ads in Hispanic newspapers and on Hispanic grocery stores, supermarkets and restaurants, and announce the program on Hispanic radio stations and television. Whenever possible the information should be provided in Spanish and should include that the program is free of charge or low cost.

\section{Implementation Stage}

When delivering a program to Hispanic audiences, keep in mind that you should emphasize family values, cultural heritage, teamwork, group learning, and focus on maintaining audience attention. Establishing good communication with the participants and involving them in different learning activities will lead to greater program success. Tips that can help accomplish this include:

- Have bilingual professionals handle registration.

- Take some initial time in the beginning of the program to socialize in order to understand the audience and build relationships with the participants. This step is necessary in order to get to know the group better. As people begin to know you and the other participants, they develop trust, and it will be possible to achieve better results since they feel ownership with the group.

- Proceed slowly, thoughtfully, and incrementally. Deliver only a small amount of instruction at once. This will enable the audience to better grasp the important concepts and ideas that are necessary to understand the whole program.

- Be sure to establish and communicate with participants through the use of clear and measurable objectives. Use these objectives as building blocks so that participants can see how they are progressing.

- Because there are many different forms of Spanish language, when translating existing material into Spanish, adapt it for a specific targeted audience rather than simply translating it literally.
- Use classroom settings that enable hands-on and experiential learning. These could include computer-aided lectures using clear examples, numerous pictures, and understandable text with bilingual content. Include do-it-yourself exercises by letting each participant do the work after proper instruction and material is given out to him/her, for example letting each person do grafting on a plant.

- Messages must be simple, brief and clear, keeping in mind that the language used must be appropriate to the educational level of the target audience. It may be necessary to use Spanglish (a mixture of Spanish and English in words or sentences). According to Johnson (1999), there are two basic approaches to Spanglish, with countless variations: code-switching (mixing) and borrowing. Code-switching is moving from one language to another in a normal conversation [ex: "it is very important to honor your abuelitas (grandparents)"]. Borrowing is the adaptation of an English word into a Spanish form [ex: "Quiero parquear (park) el coche"].

- Encourage participants to actively discuss the topic being addressed. This way you as the educator can obtain useful information about the participants' previous and new knowledge and understanding about the topic. This will help you improve the program and focus on the most pertinent information. Moreover, oral discourse improves retention of information among those who are actively involved.

- Prepare appropriate handouts and printed materials for attendees as reinforcement of the educational activities and for future reference.

- Keep in mind that each participant appreciates some type of recognition; for example, giving them a bilingual diploma or certificate upon completion of an activity or set of activities which are part of a comprehensive educational program.

\section{Evaluation process}

According to the National Academy of Sciences (2003) a solid evaluation process is needed so that 
materials can be judged as efficacious before being introduced to clientele. Also, a program of ongoing (formative) evaluation is important to assure that the target population understands the key concepts and that the program continues to improve.

- Pilot test educational materials with the target population to assess items such as appropriate messages, literacy level and readability, terminology, and graphics.

- Obtain and use feedback from trainees to determine comprehension level of materials.

- Evaluate various delivery methods to determine which practices work best; for example, PowerPoint slides, oral presentation, hands-on activities, visuals, or a mixture of multiple methods, etc. Also determine if the programs learning objectives were reached, for determining any need to follow-up and future program needs.

- The National Academy of Sciences (2003) identified the following criteria when evaluating educational programs for appropriateness with Hispanic audiences:

- Whether materials for Hispanic workers are presented in a manner that is "culturally and linguistically competent," comfortable to the worker, and not offensive;

- Whether materials are grammatically correct but in the vernacular of the workers, even when it may be a mix of Spanish and English;

- Whether the information provided is technically sound for their specific needs; and,

- Whether the subject matter is compatible with audience priorities and needs.

\section{Summary}

Hispanics are a major part of Florida's population, and it is critical that Cooperative Extension take steps towards addressing their educational needs. By focusing on their specific needs across the three phases of program development, extension educators will encounter greater success and impact with this important clientele group.

\section{Success Story}

An example of an effective program developed to reach Hispanics is the Hispanic Worker Family Health and Safety Fair held at Milander Park (an auditorium in Hialeah, Florida) on March 27, 2004. It was coordinated by the Occupational Safety and Health Administrations (OSHA) Region IV, Ft. Lauderdale, Florida Office; the University of South Florida (USF), College of Public Health Safety Florida Consultation Program; and the USF/OSHA Training Institute. The fair was developed to promote outreach to Hispanic families and "hard to reach" employees, especially those individuals unable to read and/or understand instructions in English. It focused on educating Hispanic workers and their families on workplace safety and health issues to help reduce injuries and fatalities, especially in the construction and landscaping industries. Over three hundred workers and their families attended the fair, which included twenty-four safety training workshops, health screenings and childrens vaccinations. The workshops, offered several times throughout the day by safety experts lecturing exclusively in Spanish, covered eight safety and health training subjects. Workers were encouraged to attend the safety training workshops through an incentive program. This program offered whoever attended a minimum of three sessions the chance to win a 1995 Chrysler Concorde. In addition, the fair attendees had the opportunity to take part in free health screenings which included among others, checking for high blood pressure, heart rate and pulmonary condition, cholesterol levels, eye examinations, and information and shots to prevent childhood diseases. "The fair was a tremendous success, training about two hundred workers in several of the twenty-four sessions conducted, while about one hundred of their spouses and children participated in safety and health clinics (http://www.osha.gov). 


\section{Bibliography}

Bernard, S., Carroll, D., Gabbard, S., Hernandez, T., Samadrick, R. (2005). A Demographic and

Employment Profile of United States

Farmworkers. Findings from The National Agricultural Workers Survey (NAWS)

2001-2002, 9. Retrieved July 28, 2005 from

http://dol.gov

Bocanegra, M., Warrix, M. (1998). Keys to

Building Successful Training Programs for

Hispanic Family Day Care Providers. Journal of

Extension, 36, 6. Retrieved February 25, 2005

from http://www.joe.org

Johnson, A. (1999). That curious mixture of English and Spanish is here to stay. The

Broadsheet. Retrieved August 1, 2005 from

http://www.spainview.com/spanglish.html

Knoche, L., Zamboanga, B. (2003). Voices

from College Student Mentors: Implications for

Extension Programming with Latino Youth.

Journal of Extension, 41, 3. Retrieved February

2, 2005 from http://www.joe.org

National Academy of Sciences. (2003). Safety

is Seguridad: A Workshop Summary. Retrieved

May 15, 2005 from http://www.nap.edu 